\title{
Mirror Foot: A Case Report with Review of Literature
}

\author{
${ }^{1}$ Tribhuwan NS Gaur, ${ }^{2}$ Harish Rao
}

\begin{abstract}
Introduction: Mirror foot is a very rare and complex congenital anomaly. We report the case of a 1-year-old child who was treated surgically. At 3 years follow-up, the results were satisfactory. We report this case for its rarity, unusual presentation, and successful treatment.
\end{abstract}

Keywords: Excision, Mirror foot, Preaxial polydactyly.

How to cite this article: Gaur TNS, Rao H. Mirror Foot: A Case Report with Review of Literature. J Foot Ankle Surg (Asia-Pacific) 2018;4(3):43-46.

Source of support: Nil

Conflict of interest: None

\section{INTRODUCTION}

Polydactyly is a condition of the hand or foot with more than five fingers or toes. The term polydactyly was coined by the Dutch Physician Theodor Kerckring in 1670.

Congenital anomalies of the limb are classified into seven categories proposed by Frantz and $\mathrm{O}^{\prime}$ Rahilly ${ }^{1}$ and modified by Swanson ${ }^{2}$ based on embryonic failure. The categories described are failure of formation of parts, failure of differentiation, duplication, overgrowth, undergrowth, congenital constriction band syndrome, and generalized skeletal abnormalities.

Polydactyly belongs to the category of duplication. Research has shown that the majority of congenital anomalies occur during the 4-week embryologic period of rapid limb development. ${ }^{3}$

Polydactyly has been associated with 39 genetic mutations. ${ }^{4}$

Polydactyly occurs as an isolated congenital condition or as a part of a genetic syndrome with multiple congenital anomalies. The reported anomalies in association with mirror foot are mirror hands, ${ }^{5}$ tibial hemimelia (various degrees of hypoplasia of tibia), ${ }^{6}$ fibular dimelia (absent tibia with duplication of fibula), ${ }^{7,8}$ and Laurin-Sandrow syndrome. ${ }^{9}$

\footnotetext{
${ }^{1}$ Associate Professor, ${ }^{2}$ Professor

${ }^{1,2}$ Department of Orthopedics, People's College of Medical Sciences \& Research Centre, Bhopal, Madhya Pradesh, India
}

Corresponding Author: Tribhuwan NS Gaur, Associate Professor, Department of Orthopedics, People's College of Medical Sciences \& Research Centre, Bhopal, Madhya Pradesh, India Phone: +919424344282, e-mail: tribhuwan_dr@rediffmail.com
Morphogenetically, the malformation can be considered as a process of bifurcation of one or several fingers or toe rays in the longitudinal axis progressing from distal to proximal. In addition to simple duplication, multiple duplications also occur to the extent of creating a double Hand (diplocheiria) or a double foot (diplopodia). ${ }^{10}$

Polydactyly of foot is a common foot anomaly accounting for $45 \%$ of congenital foot abnormalities ${ }^{11}$ and occurs bilaterally in 40 to $50 \%$ cases.

Temtamy and McKusick have described polydactyly based on the location of extra digit: Preaxial (medial ray), central, and postaxial (lateral ray). ${ }^{12}$ Postaxial polydactyly occurring in $80 \%$ of the patients is often asymmetric. Preaxial polydactyly affects the big toe and occurs in $15 \%$ of patients, while central duplication occurs in the remaining $5 \%$, often duplicating a hypoplastic metatarsal ray. ${ }^{13}$

An extreme form of preaxial foot polydactyly has been coined the term mirror foot or preaxial mirror polydactyly ${ }^{14}$ or has been considered the same as diplopodia. ${ }^{14}$ For the diagnosis of mirror foot, there has to be a mirror image polydactyly on the medial aspect of foot. However, there is a debate regarding the fulfilment of the criteria, particularly the duplication of all the tarsal and metatarsal bones on the medial side of the foot. There is no universal agreement on what constitutes a mirror foot. ${ }^{15}$ While some authors consider mirror foot as any foot with mirror image polydactyly, ${ }_{1}^{16}$ others ${ }^{17}$ believe that mirror duplication of all the skeletal elements of the foot on the tibial aspect must be present to fulfil the criteria for diagnosing a mirror foot. There are others who suggest that feet with supernumerary rays situated preaxially (i.e., medial to the first ray), but with characteristics of postaxial toes be considered as mirror feet. ${ }^{14}$ Preaxial mirror polydactyly is distinctly rare with only 30 cases reported in literature. ${ }^{18,19}$

We report a case of preaxial mirror polydactyly with nine toes with eight metatarsals in the right foot of a 12-month-old male child. We report this case for its rarity, unusual presentation, and successful surgical treatment.

\section{CASE REPORT}

A 12-month-old male child was brought to our outpatient department with nine toes in his right foot.

There were four duplicated toes between the welldeveloped preaxial great toe and the four postaxial normal toes (Fig. 1). There was full-term normal delivery at home. There was no history of congenital malformations. On 


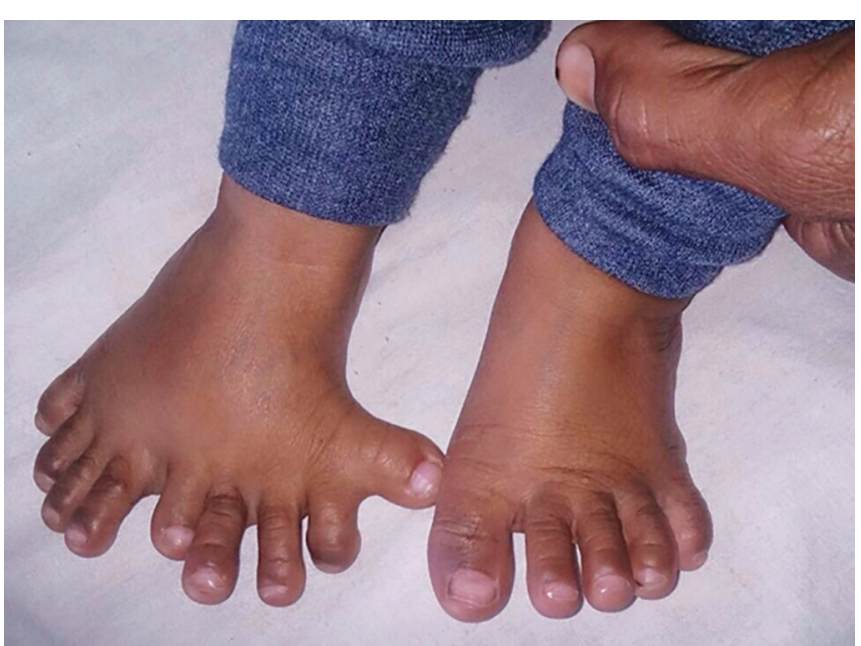

Fig. 1: Photograph at 1 year of age showing preaxial polydactyly with nine toes

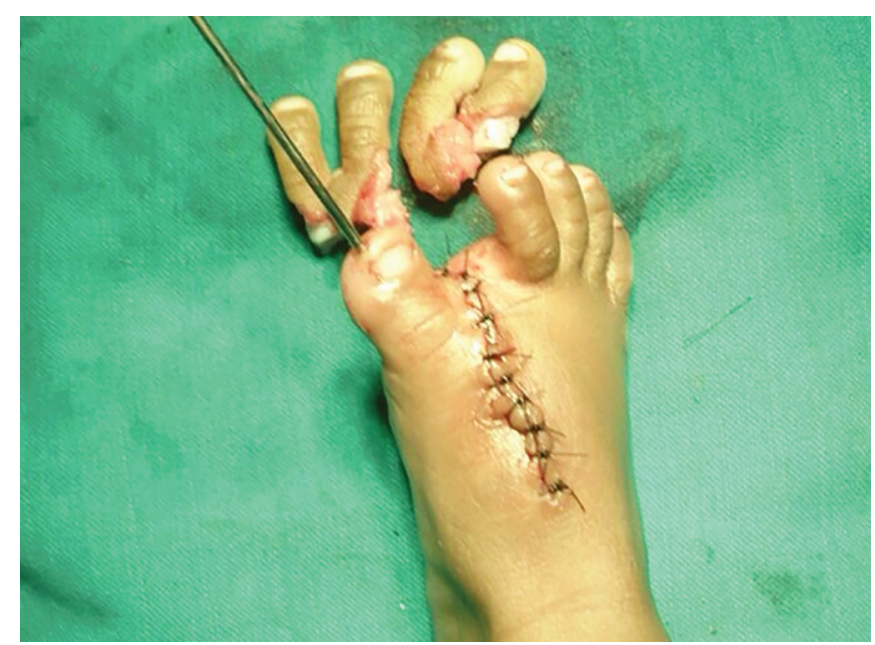

Fig. 3: Intraoperative photograph showing the excised toes and reposition and stabilization of great toe using "K" wire

examination, there was no abnormality in the spine, upper limbs, and lower limbs. The hip, knee, ankle, subtalar and metatarso phalangeal joints of the feet were normal and showed no abnormality. However, the child was diagnosed to have a severe sensorineural auditory defect. Radiograph of the foot revealed nine fully developed toes with eight metatarsals (Fig. 2). The metatarsal of the preaxial great toe was additionally bearing the accessory toe. Based on the clinicoradiological examination, a diagnosis of mirror foot was made. The great toe was at an angle of $70^{\circ}$ from the long axis of the foot. A wedge resection of the four supernumerary duplicated toes was done. After the excision of the toes, the gap was approximated by bringing the first ray laterally and was fixed by passing the " $\mathrm{K}$ " wire (Kirschner's wire) from the tip of distal phalynx of the great toe across the first metatarsal further into the midfoot after realigning the great toe over the first metatarsal and release of the abductor hallucis muscle and the metatarsophalangeal joint capsule on the medial side (Fig. 3).

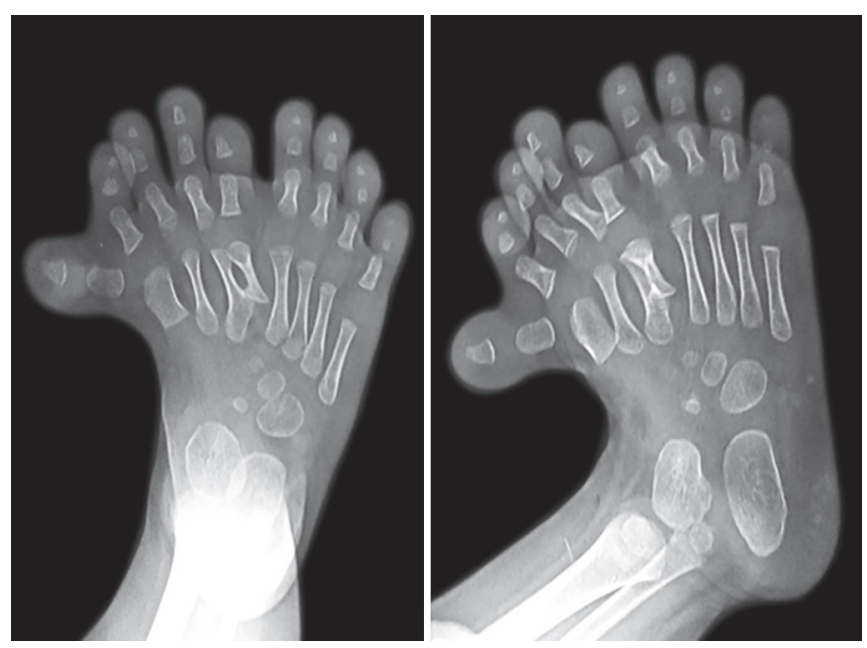

Fig. 2: X-ray anteroposterior and oblique views of foot showing eight metatarsals and nine toes. The preaxial great toe is well formed

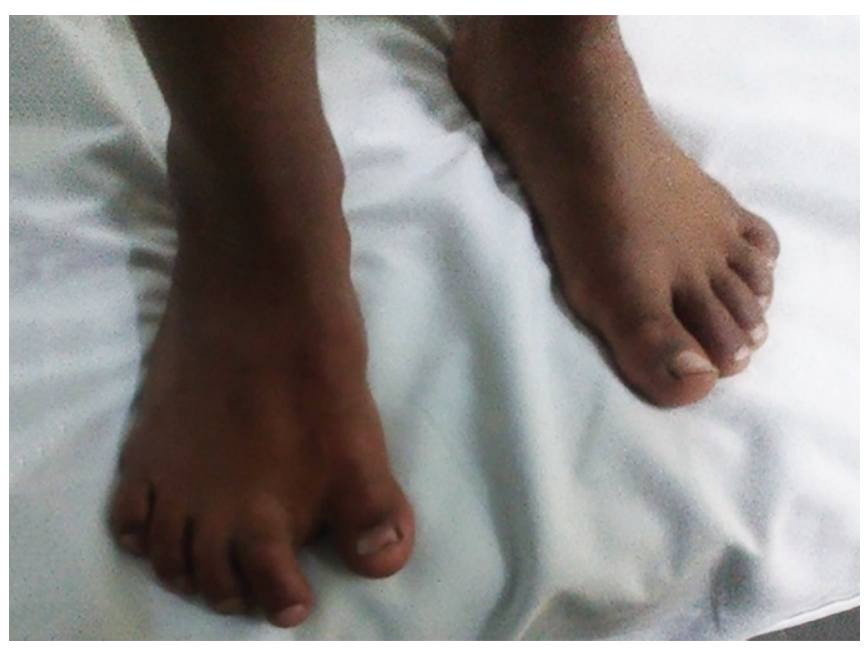

Fig. 4: Clinical photograph at 4 years of age comparing the feet; the right foot showing short first ray and a normal contour of foot

Soft tissues were sutured to avoid any tension on the suture line. Postoperatively, a long leg slab was given to facilitate wound management. At the time of discharge, a below-knee cast was given. The cast was removed at 4 weeks and the " $K$ " wire at 6 weeks. The postoperative course was uneventful until the removal of cast and " $\mathrm{K}$ " wire. The patient turned up for follow-up after nearly 3 years. Shortening of the great toe by $2 \mathrm{~cm}$ was noted. No evidence of hallux varus or splaying of the foot was noted (Fig. 4). The patient was asymptomatic and could run and play as any other child. X-ray was taken of the foot to reveal hypoplastic first ray with a shortened first metatarsal and also proximal and distal phalanges (Fig. 5).

\section{DISCUSSION}

Polydactyly of foot is a relatively common anomaly of the foot. ${ }^{20}$

There is no consensus regarding the definition of mirror foot. It has been suggested by some that the 


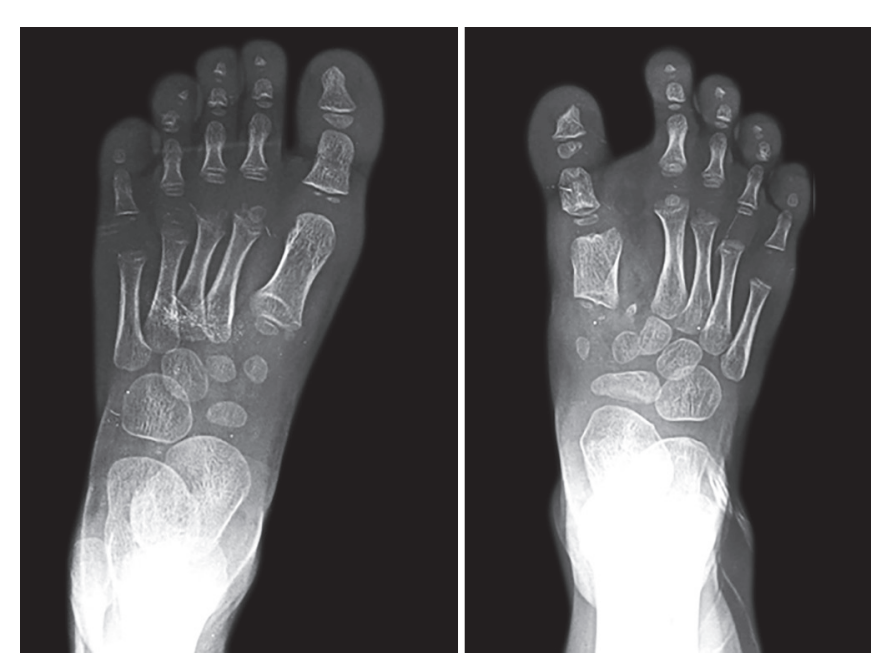

Fig. 5: X-ray of feet at 4 years postoperative follow-up showing a short stumpy first metatarsal and a restored alignment of the first ray of the right foot

presence of accessory tarsal bones differentiates it from polydactyly. ${ }^{19}$ However, some have not included it because of its variability. ${ }^{14}$ The term preaxial mirror polydactyly has been coined to include feet with supernumerary rays situated medial to the first ray (preaxially) with characteristics of postaxial toes. Preaxial mirror polydactyly (mirror foot) is an extremely rare congenital deformity of the foot. ${ }^{14}$ Preaxial mirror polydactyly is distinctly rare with only 30 cases reported in the literature. ${ }^{18}$

Three signaling centers that control limb development have been described: Apical ectodermal ridge (AER), zone of polarizing activity (ZPA), and the wingless-type (Wnt) signaling center. ${ }^{21}$

Limb buds mark their appearance as lateral outgrowths of body wall at about 5-mm stage in human embryonic development. Lower limb buds appear a little later. As the limb bud is formed, the ectoderm along the dorsal tip of the bud is induced by underlying somatopleuric mesoderm to form a ridgelike thickening at dorso-ventral boundary of the limb bud. The thickening is called AER. The AER influences the limb mesenchyme to initiate the growth and development of the limb in a proximo-distal axis. On the posterior margin of the limb bud, the mesenchymal cells aggregate to form the ZPA, which signals the growth and development in the antero-posterior axis. ${ }^{22}$ Experimentally, mirror image digit duplication has been produced by transplantation of ZPA to the cranial portion of limb bud. ${ }^{23}$ The Wnt signaling center induces the underlying mesoderm to adopt the dorsal characteristics. ${ }^{21}$ Digital rays and toes in the foot plates are formed by the mesenchymal condensation during the 7 th week. ${ }^{20}$

Polydactyly has been associated with 39 genetic mutations. ${ }^{4}$ A number of gene loci have been identified that are responsible for human polydactyly phenotypes. Genes, such as GL13 and SHH have been related to polydactyly. Mutations in $\mathrm{SHH}$ genes may be responsible for mirror image digits. ${ }^{23}$

Preaxial mirror polydactyly can be associated with fibular dimelia with complete tibial aplasia,,24 tibial aplasia without fibular duplication, ${ }^{25}$ tibial hypoplasia, ${ }^{6,17}$ and dysplastic trapezoidal tibia. ${ }^{17}$

There is association of polydactyly with several syndromes: Holt-Oram, Down, cephalopolysyndactyly, faciodigital, Rubinstein-Tayabi, Ellis Van Creveld, Lawrence-Moon-Bardet-Biedl, and Pallister-Hall. ${ }^{20}$

The etiology is still elusive. Among the few cases reported, the number of toes varied from 7 to 9 with equal, one less, or more number of metatarsals. ${ }^{18,26,27}$

In our case, the great toe was in $70^{\circ}$ varus and four supernumerary toes were interposed between the preaxial great toe and the four postaxial normal toes in all making it a nine-toed right foot with eight metatarsals. The age of presentation in different reported cases varied from 4 months to 40 years and also the age at which surgery was done was from 1 to 7 years. All the few operated cases with follow-up underwent wedge resection of the supernumerary toes with excision of the accessory tarsal bones. There being no directives of the timing of definitive surgery, revision, or staged surgery in literature, we operated at 1 year at just about walking age of patient excising all the supernumerary toes and accessory metatarsal bones. We did not find any accessory tarsal bones. As per general principles, it is prudent to preserve the most developed toe with intact ray in order to restore the normal contour of the foot. Complications, such as hallux varus, splaying of foot, and shortening of first metatarsal were kept in mind before surgery and discussed with the patient's parents. At 3 years postsurgery follow-up, the patient could wear his shoes and participate in all activities just as other children. We ensured that there were no duplicated tarsals as has been advised by some authors to avoid a revision surgery at a later stage. ${ }^{26}$

However, the shortening of the first metatarsal about $2 \mathrm{~cm}$ was not addressed at this stage, as this was not disabling to the patient; except for cosmetic reasons, the patient's attendants were very satisfied with the functional outcome.

The classification of foot polydactyly is myriad in literature. Fukazawa et $\mathrm{al}^{18}$ have proposed a classification based on mirror hand classification with some recommendations for treatment. Some have classified polydactyly based on location of duplicated toes and the syndrome associated. ${ }^{11}$ Watanabe et $\mathrm{l}^{28}$ proposed a classification based on the location of supernumerary toes into preaxial, central, and lateral and further subdivided it into tarsal, metatarsal, proximal, and distal phalangeal 
groups. This classification has profound implication in planning surgery; hence, it is widely popular.

The success of our case can be attributed to early surgery before the child started walking, ensuring no accessory tarsals, and delayed removal of " $\mathrm{K}$ " wire at 6 weeks to ensure the stability of great toe in the realigned position.

\section{REFERENCES}

1. Frantz $\mathrm{CH}, \mathrm{O}^{\prime}$ Rahilly R. Congenital skeletal limb deficiencies. J Bone Joint Surg Am 1961 Dec;43(8):1202-1224.

2. Swanson AB. A classification for congenital limb malformations. J Hand Surg Am 1976 Jul;1(1):8-22.

3. Watt AJ, Chung KC. Duplication. Hand Clin 2009 May;25(2):215-227.

4. Biesecker LG. Polydactyly: how many disorders and how many genes. Am J Med Genet 2002 Oct;112(3):279-283.

5. Hersh JH, Dela Cruz TV, Pietrantoni M, von Drasek-Ascher G, Turnquest MA, Yacoub OA, Joyce MR. Mirror image duplication of the hand and feet: report of a sporadic case with multiple congenital anomalies. Am J Med Genet 1995 Nov;59(3):341-345.

6. Skoll PJ, Silfen R, Hudson DA, Bloch CE. Mirror foot. Plast Reconstr Surg 2000 May;105(6):2086-2088.

7. Bayram H, Herdem M, Temocin AK. Fibular dimelia and mirror foot without associated anomalies. Clin Genet 1996 Jun;49(6):311-313.

8. Rivera RE, Hootnick DR, Gingold AR, Levinsohn EM, Kruger LM, Packard DS Jr. Anatomy of a duplicated human foot from a limb with fibular dimelia. Teratology 1999 Nov;60(5): 272-282.

9. Kantaputra N. Laurin-Sandrow syndrome with additional associated manifestations. Am J Med Genet 2001 Jan;98(3):210-215.

10. Miura T. Polydactyly in Japan. Handchirurgie 1980 Feb;12(1-2): 39-46.

11. Son WG, Kwon ST, Lee SW. Simple classification of foot polydactyly based on the status of Metatarsal bone and Varus deformity. J Korean Soc Plast Reconstr Surg 2004 Jul;31(4): 501-505.

12. Christensen JC, Leff FB, Lepow GM, Schwartz RI, Colon PA, Arminio ST, Nixon P, Segel D, Leff S. Congenital polydactyly and polymetatarsalia: classification, genetics, and surgical correction. J Foot Ankle Surg 2011 May-Jun;50(3):336-339.

13. Eberson, CP.; Schiller, J. Common paediatric foot and ankle condition. In: Di Giovanni C, Greisberg J, editors. Core knowledge in orthopaedics: foot and ankle. Philadelphia (PA): Elsevier; 2007. p. 159.

14. Vergese R, Shah H, Rebello G, Joseph B. Preaxial mirror polydactyly associated with tibial deficiency: a study of the patterns of skeletal anomalies of the foot and leg. J Child Orthop 2007 Mar;1(1):49-54.

15. Bonnet F, Garrido I, Haddad R, Pavy B, Mitrofanoff M. Complex polydactyly of the limbs: mirror foot. Report of two cases and review of literature. Ann Chir Plast Esthet 2005 Jan;50(4):323-327.

16. Mastumoto N, Ohashi H, Kato R, Fujimoto M, Tsujita T, Sasaki T, Nakano M, Miyoshi O, Fukushima Y, Niikawa N. Molecular mapping of a translocation breakpoint at 14q13 in a patient with mirror-image polydactyly of hands and feet. Human Genet 1997 Mar;99(4):450-453.

17. Karchinov K. Congenital diplopodia with hypoplasia or aplasia of the tibia. A report of six cases. J Bone Joint Surg Br 1973 Aug;55(3):604-611.

18. Fukazawa $\mathrm{H}$, Kawabata $\mathrm{H}$, Matsui Y. Mirror foot: treatment of three cases and review of the literature. J Child Orthop 2009 Aug;3(4):277-282.

19. Sudesh P, Kumar V, Jain M, Patel S. Mirror foot and our surgical experience: a case report and literature review. Foot (Edinb) 2010 Mar;20(1):44-45.

20. Belthur MV, Linton JL, Barnes DA. The spectrum of preaxial polydactyly of foot. J Paediatr Orthop 2011 Jun;31(4):435-447.

21. Kozin SH. Upper-extremity congenital anomalies. J Bone Joint Surg Am 2003 Aug;85-A(8):564-576.

22. Mishra A, Nelson K, McArthur P. Mirror foot: a reflection on three cases. J Plast Reconstr Aesthet Surg 2010 Dec;63(12):2146-2151.

23. Shoenwolf, G.; Bleyl, S.; Brauer, P.; Francis-West P. Larsen's human embrryology. 4th ed. Philadelphia (PA): Churchill Livingstone; 2009. pp. 621-632.

24. Ganey TM, Carey TP, O'Neal ML. Morphologic and radiographic characterization of fibular dimelia. J Pediatr Orthop B 2000 Oct;9(4):293-305.

25. Martin RA, Jones MC, Jones KL. Mirror hands and feet with a distinct nasal defect, an autosomal dominant condition. Am J Med Genet 1993 Apr;46(2):129-131.

26. Vlahovic AM, Pistignjat BS, Vlahovic NS. Nine toes; mirror foot deformity. Indian J Orthop 2015 Jul-Aug;49(4):478-481.

27. Omar S, Mehdi MD, Banerjee P. Bizarre case of polydactyly with right mirror foot. Int J Anat Res 2014 Apr-Jun;2(2): 333-335.

28. Watanabe H, Fujita S, Oka H. Polydactyly of the foot: an analysis of 265 cases and a morphological classification. Plast Reconstr Surg 1992 May;89(5):856-877. 